\title{
Mating Behaviour in Different Size Males of Macrobrachium idae (Heller, 1862)
}

Soundarapandian $P^{*}$, Sudhakar S, Varadharajan D and Dinakaran GK

Centre of Advanced Study in Marine Biology, Annamalai University, Tamil Nadu, India

\begin{abstract}
Twenty seven commercial Macrobrachium species are found in Asia and the Pacific Ocean. Most of them are inhabited in freshwater except few are exclusively marine oriented. Few species live in brackish water especially in the mouths of rivers. A close examination of $M$. idea males reveals that three distinct morphotypes based upon size ranking, the ratio of claw length to body length (relative claw length) which included small male (SM), medium sized male (MS) and bigger sized male (BS). The mating behaviors of three different males 4 experiments were conducted by (1) 3 BS males $(90-100 \mathrm{~mm})$ vs. female $(50-75 \mathrm{~mm})$; (2) $3 \mathrm{MS}$ males $(60-75 \mathrm{~mm})$ vs. female $(50-75 \mathrm{~mm})$; (3) 3 SM males $(45-55 \mathrm{~mm})$ vs. female $(50-75 \mathrm{~mm})$; (4) 1BS male, $2 \mathrm{MS}$ males and $3 \mathrm{SM}$ males vs. female $(55-75 \mathrm{~mm})$. The mating behaviour of $M$. idae was divided into four phases such as (I) Contact: When the male recognize the pre-mating female, it moves towards the female and starts approaching her. (II) Guarding: During this behaviour, the male encircled the female with his second pereiopods in a way that her tail region. (III) Mounting: After shell getting slightly hardens; the male grasps the female and begins to mount the female. After that using third and fourth pereiopods male started to clean the brood chamber to deposit the spermatophore. (IV) Mating: Took place when the female turned on her back, so that her ventral side was up. Next moment the spermatophore was ejected and deposited on the ventral median thoracic region of the female. After mating the pair was separated and again the male protects the female until the shell hardens completely. The $89.46 \%$ of the females were successfully fertilized in the presence of BS males and only $4.56 \%$ failed to become berried. In the cases of MS and SM males, successful fertilization was happened in $34.5 \%$ and $38 \%$ of the females and infertility was recorded for $34.37 \%$ and $40.99 \%$ of the females, respectively. The reproductive success of the BS male was significantly higher than that of the other two morphotypes $(P<0.05)$.
\end{abstract}

Keywords: M. idea; Act of pairing; Morphotypes; Reproduction; Population dynamics

\section{Introduction}

In crustaceans there is a competition for mating especially among the males. The aggressive and dominant males win over less aggressive and subdominant males [1-5]. The male reproductive success depends on male-male competition and aggression. This is very common in polygamous species. The individuals who are at a competitive disadvantage sometimes adopt an entirely different group of reproductive behaviours [6]. The present study evaluates the relative reproductive potential of three different size males of $M$. idae by examining their mating strategy in close quarter in an aquarium and to arrive at a qualitative evaluation of each of these morphotypes (representing three different developmental stages) according to each type's specific physical characteristics, typical behaviour and probability of achieving successful fertilization.

\section{Materials and Methods}

\section{Collection}

The animals were collected from Ponnanthittu (Lat.11 $28^{\prime} 41^{\prime \prime} \mathrm{N}$; Long. $79^{\circ} 45^{\prime} 30^{\prime \prime} \mathrm{E}$ ) waters which is located $2 \mathrm{~km}$ south to Parangipettai and connected with Vellar estuary. The prawns were caught by the fisherman with the help of trap, line and hand-net and scoop net. The specimens collected from the fisherman were ranged from 30 to 110 $\mathrm{mm}$ in length. Totally 150 specimens were collected and transported to the laboratory in live condition by keeping them in bucket containing freshwater and aeration. After reaching the laboratory they were washed carefully with distilled water to remove the dust and algal particles.

\section{Selection of three different sized males}

A close examination of $M$. idae males reveals that three distinct morphotypes based upon size ranking and the ratio of claw length to body length (relative claw length). Three male categories include (a) small males (SM) (b) medium sized (MS) males and (c) bigger sized (BS) males (Table 1). The selection of males was performed according to the morphologically distinctive characteristics of the three male categories and females were based on their state of sexual maturation as determined by gonad development [7]. The females used in each experiment were sexually matured and mostly in the size range of 45 to $80 \mathrm{~mm}$.

\section{Experimental setup}

Mating probability of SM, MS and BS males was examined in separate glass aquarium by stocking each of these morphotypes together with a female. In other set of experimental group all three different sized males (SM, MS and BS males) were stocked together with a female in glass aquarium. The rate of female fertilization by the subordinate SM, MS and BS males in separate glass aquarium and female fertilized in the glass aquarium where stocked with all three different sized males indicates that the actual probability of SM and MS males to achieve a

${ }^{*}$ Corresponding author: Soundarapandian P, Faculty of Marine Sciences Centre of Advanced Study in Marine Biology, Annamalai University, Parangipettai-608 502, Tamil Nadu, India, Tel: 04144-243223; Fax: 04144243553; E-mail: soundsuma@gmail.com

Received November 11, 2013; Accepted December 10, 2013; Published December 12, 2013

Citation: Soundarapandian P, Sudhakar S, Varadharajan D, Dinakaran GK (2013) Mating Behaviour in Different Size Males of Macrobrachium idae (Heller, 1862). J Cytol Histol 5: 205. doi:10.4172/2157-7099.1000205

Copyright: (c) 2013 Soundarapandian P, et al. This is an open-access article distributed under the terms of the Creative Commons Attribution License, which permits unrestricted use, distribution, and reproduction in any medium, provided the original author and source are credited. 


\begin{tabular}{|c|c|c|c|}
\hline S. No & Category & BS male & MS male \\
\hline $\mathbf{1}$ & Body size & Large & Medium \\
\hline $\mathbf{2}$ & Relative claw length $(\mathrm{cm})$ & $16-17.5$ & $11.5-13$ \\
\hline $\mathbf{3}$ & Mobility & Mainly resting and self-grooming & Mainly resting and self-grooming \\
\hline $\mathbf{4}$ & Agonistic competition & Aggressive and dominant & Aggressive and subdominant \\
\hline $\mathbf{5}$ & Courtship & Protecting and grooming & Never observed courting \\
\hline $\mathbf{6}$ & Copulatory attempts & Must turn over & Mainly exploring \\
\hline
\end{tabular}

Table 1: Qualitative comparison of physical and behavioral characteristics of the three male morphotypes of $M$. idea.

successful copulation in a situation more similar to that prevailing in nature where BS males are guarding and protecting receptive females.

The following stocking combinations were tried in the present study.

1. 3 BS males $(90-100 \mathrm{~mm})$ vs. female $(50-75 \mathrm{~mm})$.

2. $3 \mathrm{MS}$ males $(60-75 \mathrm{~mm})$ vs. female $(50-75 \mathrm{~mm})$.

3. $3 \mathrm{SM}$ males $(45-55 \mathrm{~mm})$ vs. female $(50-75 \mathrm{~mm})$.

4. 1BS male $2 \mathrm{MS}$ males and $3 \mathrm{SM}$ males vs. female $(50-75 \mathrm{~mm})$.

One glass aquarium (for a close observation) and two fiber glass tanks were kept for each stocking combinations. Whenever a male went through a morphotypic transformation, died, or suffered from physical injury (such as lost of claws while moulting or fighting), that was replaced by another male of a similar morphotype. Altogether, all males in each aquarium were replaced 3-4 times due to injuries within the entire observation period. In addition to the males, a female with ripe gonads was present at any given time in each aquarium. Whenever a female became berried, it was replaced by an equivalent female, and was transferred into a separate aquarium to observe the embryonic development. When a receptive female in an observation aquarium either did not became berried, or lost all eggs within 48 hours from the pre-mating moult, it was replaced by another female and failure of fertilization was recorded.

\section{Experimental conditions}

Observations were carried out in glass aquarium $(58 \times 58 \times 37$ $\mathrm{cm}$ ) equipped with aerators to satisfy the need of dissolved oxygen (5 ppm) and also temperature control devices to maintain optimum temperature $\left(27-28^{\circ} \mathrm{C}\right)$ throughout the experiment. In each aquarium six or seven plastic pipes was placed $(3 \mathrm{~cm}$ in diameter and $5-15 \mathrm{~cm}$ long) which served as shelters for newly moulted individuals. All experimental animals were fed daily with chopped fish and clam meat. Uneaten feed was removed daily from each aquarium and fiber glass tanks by siphoning. Glass aquarium was checked daily for moults, male morphotypic transformations and berried females. Berried females were kept isolated in fiber glass tanks $(45 \times 30 \times 37 \mathrm{~cm})$ which also equipped with aerators and temperature control devices to maintain conducive environment.

\section{Observations and measurements}

Behavioural observations were carried out especially when a female entered into pre-mating moult. Special attention was given to the relative position of each individual in the aquarium to the male-female interactions (protecting and mating) and to the typical male-male interactions (agonistic behavior). Whenever a female was removed, some 48 hours after a pre-mating moult, its physical state was recorded, i.e., lost appendages, broken antennae and other signs of physical injury. Embryonic development was observed two weeks later by a microscopical examination of eggs sampled from the females abdomen and served as the ultimate proof of successful fertilization. The percentages of successful fertilizations, failures to fertilize, female mortalities due to physical injuries made by males soon after premating moult and other female mortalities unrelated to interactions with males were calculated.

\section{Results}

\section{General mating behaviour}

The mating behaviour of $M$. idae was divided into four phases in general as given below.

\section{Contact}

When the male recognizing the pre-mating female, it moved towards the female and started approaches her with his shoulders perked up. With his first antenna stretched forward gently grasps her uropod, pleopods etc., with his first pereiopods.

\section{Guarding}

After male contacts the newly moulted female, the male guards the female. During this behaviour, the male encircled the female with his second pereiopods in a way that her tail region faces his head region. This was continued for 1.30-3 hours until the shell slightly hardens.

\section{Mounting}

After the shell gets slightly harden, the male grasps the female and begins to mount the female. In the mean time he begins to search for the sternum of the female using the dactylae of his third and fourth pereiopods on which his spermatophore is to be deposited. The male supports female body with his long second and fifth pereiopods throughout mounting and mating. When he was recognizing her sternum near the bases of her last three pairs of pereiopods he began to turn her upside down using his first, third and fourth pereiopods. After that using third and fourth pereiopods male was started to clean the brood chamber.

\section{Mating}

Mating took place when the female was turned on her back, so that her ventral side was up. Immediately after this the male strongly bends backwards with a vigorous beating of pleopods. Pressing down from above, he brought his genital pores very close to the female's ventral thoracic region without touching the sternum. Next moment the spermatophore was ejected and deposited on the ventral median thoracic region of the females. After mating the pair was separated and again the male protects the female until the shell hardens completely.

\section{Experimental setup 1}

In this setup 3 BS males (90-100 $\mathrm{mm}$ ) were stocked with a matured female. When the males encountered the pre-mating female there was a strong competition between the males for mating. The stronger male started to court the female from other males. Once he was won over 
than he tried to contact the female and eventually mounted her. After mounting, the male turned over the female and started grooming the female brood chambers to remove the dust and other algal particles from brood chamber before the deposition of the spermatophores.

\section{Experimental setup 2}

In this setup 3 medium sized (MS) males $(60-75 \mathrm{~mm})$ were stocked with a matured female. When the males met with the pre-mating female there was a fight between the males for mating. At last the male which won the competition was turning over the female and finally went for mating without cleaning the brood chamber and courting was totally absent.

\section{Experimental setup 3}

In this experimental setup 3, small sized (SM) males $(45-55 \mathrm{~mm})$ were stocked with a matured female. When the males encountered the pre-mating female there was a competition between males. The successful male started attracting by contact and mounting the female, then tried to turn over the female. Since the males are smaller than the female it was very difficult for him to turn the female. So the male tried to mate the female by sneaking while turning it underneath of the female and started mating without cleaning the brood chamber of the female. The small males failed to court the female and occasionally injured by the continuing attempts of the several SM males to approach her at the same time.

\section{Experimental setup 4}

In this setup, $1 \mathrm{BS}$ male, $2 \mathrm{MS}$ and $3 \mathrm{SM}$ males were stocked with a matured female. When the bigger, medium and smaller sized males were approached the pre-mating females for mating, major behavioural differences were visible between BS, MS and SM males. The BS males showed all the characters like courting, mounting and turning the female and subsequently tried to attach its spermatophore. In the BS male's territorial area the MS males were immobile. Although MS males were attracted by the female, they were easily chased away by the dominant BS male. In many instances after one or two agonistic encounters the MS males ignore the mating couple. But when the BS male was absent a series of agonistic encounters among the MS males were resulted in dominant male trying to capture the female prior to mating. BS male spend most of its time resting and grooming themselves, or actively courting and protecting the receptive female while displaying agonistic behaviour towards all other males. The SM males were highly mobile. They were the first to react to the introduction of food and were strongly attracted to receptive females. They usually avoid physical contact with superior BS and MS males by retreating into the water column whenever closely threatened by the BS and MS males. However, there were always few SM males continuously hovering around the female whether the female was alone or protected by the BS male. Occasionally SM males were attempted to sneak under the female and attached its spermatophore to the female's abdomen. The successful aggressive BS male turned the female and attached their spermatophore.

\section{Reproductive potential of the three male morphotypes}

Comparison between the relative frequencies of successful fertilizations by the three male morphotypes was presented in Table 2, experiments 1, 2 and 3 showed that the reproductive advantages of BS male were dominant over MS and SM males. The female was successfully (89.46\%) fertilized in the presence of BS males and only $4.56 \%$ female was failed to become berried. In the cases of MS and SM males, successful fertilization was $41.69 \%$ and $34.66 \%$ and the infertility was recorded $34.37 \%$ and $40.99 \%$ respectively. The reproductive success of the BS male was significantly higher than that of the other two morphotypes $(\mathrm{P}<0.05)$ (Table 3$)$.

In addition to high probability of achieving a successful fertilization, BS proved to be better guards of receptive newly moulted females than SM and MS males. Only BS males were observed to protect the females during courtship activity. Moreover, only $3.18 \%$ of the females died as a consequence of male aggression whenever BS males were present, whereas females stocked with MS and SM males, had a mortality rate of $18.74 \%$ and $19.09 \%$ respectively.

\section{Reproductive potential of SM and MS males in the presence of a dominant BS male}

In the experiment- 4 , where SM and MS males were kept together with BS males (Table 2), $70.33 \%$ of the females were successfully

\begin{tabular}{|c|c|c|c|c|c|}
\hline Experiments & Stocking combinations & Successful fertilization (\%) & Failure of fertilization (\%) & Mortality due to inflicted injuries (\%) & Natural mortality (\%) \\
\hline 1 & $3 \mathrm{BS}$ & $89.46 \pm 1.76$ & $4.56 \pm 0.42$ & $3.18 \pm 2.76$ & $2.77 \pm 4.81$ \\
\hline 2 & $3 \mathrm{MS}$ & $41.69 \pm 5.06$ & $34.37 \pm 2.12$ & $18.74 \pm 4.24$ & $5.18 \pm 1.73$ \\
\hline 3 & $3 \mathrm{SM}$ & $34.66 \pm 2.75$ & $40.99 \pm 0.86$ & $19.09 \pm 2.18$ & $5.20 \pm 2.44$ \\
\hline 4 & $\begin{array}{c}1 \text { BS male, } 2 \text { MS males } \\
\text { and } 3 \text { SM males }\end{array}$ & $70.33 \pm 5.12$ & $17.89 \pm 4.35$ & $7.39 \pm 2.31$ & $4.36 \pm 4.12$ \\
\hline
\end{tabular}

Table 2: Reproductive potential of the three male morphotypes when held separately and in combination with female (values are mean of three values \pm SE).

\begin{tabular}{|c|c|c|c|c|c|c|c|}
\hline Parameters & Source of variation & SS & df & MS & $\mathbf{F}$ & P-value & Sig \\
\hline \multirow{3}{*}{ Successful fertilization } & Between Groups & 5846.169 & 3 & 1948.723 & 124.7414 & $4.68 \mathrm{E}-07$ & \multirow{3}{*}{$P<0.05$} \\
\hline & Within Groups & 124.9768 & 8 & 15.6221 & & & \\
\hline & Total & 5971.146 & 11 & & & & \\
\hline \multirow{3}{*}{ Failure of fertilization } & Between Groups & 2431.406 & 3 & 810.4687 & 132.8111 & 3.66E-07 & \multirow{3}{*}{$P<0.05$} \\
\hline & Within Groups & 48.81933 & 8 & 6.102417 & & & \\
\hline & Total & 2480.226 & 11 & & & & \\
\hline \multirow{3}{*}{ Mortality due to inflicted injuries } & Between Groups & 584.4189 & 3 & 194.8063 & 21.78889 & 0.000332 & \multirow{3}{*}{$P<0.05$} \\
\hline & Within Groups & 71.525 & 8 & 8.940625 & & & \\
\hline & Total & 655.9439 & 11 & & & & \\
\hline \multirow{3}{*}{ Natural mortality } & Between Groups & 11.65053 & 3 & 3.883511 & 0.313206 & 0.815595 & \multirow{3}{*}{$P<0.05$} \\
\hline & Within Groups & 99.19387 & 8 & 12.39923 & & & \\
\hline & Total & 110.8444 & 11 & & & & \\
\hline
\end{tabular}

Table 3: One-Way ANOVA for the reproductive potential of the three male morphotypes (\%) when held separately and in combination with females. 
fertilized, indicating that females may readily become berried, under these experimental conditions, depending only on the ability of the male morphotypes present to complete successful mating. All reproductive relative behaviour is statistically significant (Table 3 ).

\section{Discussion}

Many scientists worked on alternative mating strategies world over [8-12]. These approaches have focused primarily on behavioural or developmental differences among individuals. Raanan and Sagi [13] described three male morphs representing successive growth stages in freshwater prawn, M. rosenbergii [14]. Kuris et al. [15] demonstrated that developmental path among the male morphs in $M$. rosenbergii are determined by feeding schedule and social interactions among individuals. Barki et al. and Kurup et al. suggested that in fact, four morphs are identifiable $[16,17]$ and that dominance hierarchies among the morphs exist, wherein removal of larger individuals induces smaller individuals to grow. However, not all individuals responded equally to this stimulus, as expected if males vary in their responsiveness to social and nutritional cues [15,18]. Other Macrobrachium species also appear to exhibit male polymorphism, $M$. dayanum, M. idae, M. malcolmsonii and M. scabriculum reviewed in [15]. In the present study M. idae also showed dominance hierarchies among the males as in $M$. rosenbergii $[19,20]$. The different male morphotypes were defined on the basis of colour and spination of the chela, behaviour and growth characteristics $[21,22]$. Kuris et al. [15] have summarized operational allometric criteria to recognize the morphotypes and describe the transition between morphotypes. The M. idella idella were classified mostly based on the size of the chelate, behaviour, and growth characteristics but not the colour of the chelate legs as in $M$. rosenbergii [23]. In the present study also $M$. idae was classified on the size of the chelate, behaviour and growth characteristics not the colour of the chelate legs.

Mating is initiated only after a female experienced the pre-mating moult. Necessity of pre-mating moult in decapods has been described by several workers. Atema [24] suggested that inter-moult females get rejected by the males, because they lack of proper sex pheromone. Antheunisse et al. [25] observed that the female Palaemonetes with ripe ovaries moult into "breeding dress", which is characterized by the presence of extra setae for egg attachment, enlargement of abdominal brood pouch and development of periodic chromatophores etc. Following the moult into "breeding dress", females became attractive and receptive to males. It is inferred that the pre-mating moult is the preparatory step for breeding purposes. In the present study, $M$. idae males were also preferred the permating females and rejected intermoult females. Just like M. idella idella [23] the females of M. idae also had ripe ovaries and enlarged brood pouch with extra setae for egg attachment.

In the present study the bigger (BS) and smaller (SM) sized males may represent two alternative ways of mating while the medium sized (MS) males may be considered an intermediate developmental stage between these two, with a relatively low mating probability as such, in the presence of a BS male. This notion is supported by the fact that both SM and BS males hardly increase in body size while MS males are characterized by a rapid growth rate $[22,26]$, thus, investing relatively little energy, if any, in reproduction during this stage of development. The BS mating strategy may rely on superiority in threatening display towards the other males, while investing a great deal of energy in developing its weaponry (large, massive claws).

In many crustaceans male's exhibit highly developed fighting structures (chelae, pereiopods). Males of these species may overtake females and hold them in a firm mating grip making it difficult to detect females have preferences. Despite these difficulties several studies indicate that females are capable of exerting preferences for certain males by exhibiting resistance to the advances of some males. For example, female tanner crabs resisted mating attempts from oneclawed males [27] and female crayfish resisted mating attempts from small males more efficiently than those from larger males [28]. In many species of females offer little resistance to males because it may be costly and dangerous, sometimes even leading to the death of the female [13]. Instead of showing overt choices, females may exert their preferences for certain males in subtle, often cryptic, behaviours that are difficult to observe or quantify. It is for these reasons that female preferences are often little known in crustacean species with coercive male mating behaviour. In the three spot crab Portunus sanguinolentus, small male invaded the breeding territories of larger male. Since the larger male had bigger chelate which displayed aggressive interaction with small male and chased away and finally placed himself in the cradle carry position. The female crab avoided the small crab and accepted the bigger crab for its aggressive interaction and eventually successful mating was happened [29]. In all of these populations, extreme sexual dimorphism involving large size and elongated chelae in males suggests that competition for mates is intense [30]. Moreover, relatively long lived individuals appear to obtain information and respond appropriately with respect to their future mating opportunities, to nutritional and social cues during development [15]. Populations of the same species appear to vary in the proportions of individuals exhibiting different male morphologies [31,32]. In the present study the bigger sized males dominated over the other medium (MS) and small sized (SM) males and the females preferred BS males than other two sizes because the bigger sized males court and protect the female by his bigger chelate leg from other males. Whereas the courting behaviour is absolutely absent in medium and small sized males.

Courtship display is an important pre-mating behaviour in carideans. Heckenlively [33] and Ameyaw-Akumfi [34] suggested that courtship reduces aggressive tendencies in the female. Antennal contact by the male with a receptive female appears important in recognizing the sexual receptivity [35]. Hamano [36] suggested that the antennal contact created a mutual understanding between the mating pairs. As in Palaemonetes pugio and P. vulgaris, the male can recognize a receptive female only after antennal contact with any surface of the female [37]. The recognition mark may be a non diffusible coating of the integument of the female [38]. However, Ling [39] suggested that the ripe female $M$. rosenbergii secretes a substance which attracts male. Gleeson [40] reported the presence of pheromone in the urine of pre and post-pubertal moulted female blue crabs. Callinectes sapidus which is elicits courtship behaviour in mature males. Similarly, males of the small shrimp, Heptacarpus paludicola respond to matable females from a distance with increased levels of activity such as, walking and swimming [41], the females may emit a water-soluble pheromone which attracts males. The presence of pheromone is not tested in the present study. However, it is clear that antennal contact is unavoidable and such contact elicits an immediate response from the female. Precopulatory mate guarding is widespread among crustaceans $[42,43]$. The explanation for this tendency in many species is moulting initiates female receptivity and chemical cues present in female urine or present on females themselves prior to this moult allows males to locate, guard and inseminate females as soon as they become receptive. Mate guarding reduces the ability of females to mate more than once, thus a male who guards a female successfully fertilizes all of her ova. If a 
male unsuccessfully guards his mate, or if he leaves her in search of other females before her receptivity is complete, the males fertilization success with that female will be eroded due to matings by other males. Sperm competition is reported to be an alternative mating strategy in crustaceans [43-45]. The guarding behaviour is an act of protecting the newly moulted female from aggression by other individuals. In the present study, $M$. idae showed this behaviour before and after mating until the females shell hardened as in M. idella idella [23]. Unfortunately Chow et al. [46] did not observe any such behaviour in $M$. rosenbergii whereas, Ling (1969) [39], Ling (1962) [47] reported such behaviour in $M$. rosenbergii, in which the pre-mating moulted female was promptly and tenderly protected by a mature male from the attack of other individuals.

Males in a wide range of crustacean species that engage in mate guarding exhibit flexibility in guarding duration in response to local sex ratios, as well as in their responses to female body size, reproductive condition, parasitemia and resistance to male guarding attempts $[43,48]$. Variability in guarding duration in response to sex ratio shows a consistent pattern in several pericardia [43]. Such behavioral flexibility is consistent with the hypothesis that mate guarding evolves as an adaptation to prevent multiple mating. Flexibility in mate guarding behaviour is evidently under strong sexual selection because males who guard ineffectively lose fertilizations to other males. Thus, the expression of this behavioural trait is consistent with the predictions of threshold inheritance of behavioral phenotypes [45]. The present study was also evident for the above reasons. Genetically variable characters likely to influence behavioural liability include individual sensitivities to crowding and to circulating hormone levels [49-51]. Other characters likely to influence mating behavior may include heritable sensitivities to pheromone concentrations [52], to the density of mating competitors [53], or to the perception of mating behavior by other individuals [54]. In $M$. rosenbergii, the $\mathrm{BC}$ (Blue claw male) males seem to enjoy most of the benefits which contribute to male reproduction success, namely, high attractiveness for females, advantage in agonistic encounters with other males, and high survival (85-100\%) probability of fertilized females following mating. The main costs associated with $\mathrm{BC}$ mating strategy involve energy expenditure in defending a territory, reduced flexibility to readjust to changing environmental conditions, and the reduced ability to moult and thereby regenerate lost limbs, resulting in a relatively short life span [13]. In the present study the BS males also showed similar behaviour as in BC males of $M$. rosenbergii and BS males of $M$ idelle idella [23]. The bigger chelate male crab of $P$. sanguinolentus enjoyed all sexual related activities and ultimately succeeded in mating with females [29].

In many species, small males invade the breeding territories of larger males by avoiding direct competition altogether. Once inside breeding territories, these "sneaker" or "satellite" males surreptitiously mate with receptive females, as occurs in isopods (Paracerceis sculpta, [55], amphipods (Microdeutopus gryllotalpa [56], Jassa marmorata [57] and in many decapods, Macrobrachium spp [13], sand bubbler crabs, Scopimera globosa [58], spider crabs, Libinia emarginata [59] and rock shrimp, Rhynchocinetes typus [60]. In each of these species, stolen matings appear to yield unconventional males but a tiny fraction of the fertilization success gained by males. That is, satellite males appear to "make the best of a bad job" [11]. In the present study unconventional males took fertilizations away from males whose fertilization success is already disproportionately large; satellite males are more successful at siring offspring than territorial males who secure no mates at all. SM males, on the other hand, were less attractive to females. However, their ability to readjust quickly to changing conditions, together with the ever-present option to shift to the MS rapid growing phase, and its associated chance of becoming a BS male, may balance the lower probability of fertilizing females while being a SM male (only $34.66 \%$ under the present experimental conditions).

In the present study the males mating strategy in Midae is dependent primarily on the individual's size ranking within the population. A direct relationship between relative size and mating behaviour was also described in the cases of M. rosenbergii [13], dung flies, Sepsis cynipsea [2] and Scatophaga stercoraria [61]. In the above cases most of the size variation was attributed to environmental causes. Constantz [5] suggested that a highly competitive environment, in which there is a high frequency of large males, may favour small, sneaking males, since territorial males primarily will be occupied with agonistic behaviour that consumes a significant fraction of their time and energy. At an evolutionary stable strategy, the relative proportions of the two male types in the population should be at an equilibrium in which the fitness of both is equal [62]. The signals by which any individual determines its relative position within the size hierarchy, and the mechanisms by which these signals are translated to mating behaviour and to the regulation of growth rate are presently unknown.

\section{References}

1. Alcock J, Jones E, Buchmann SL (1977) Male mating strategies in the bee Centris pallida fox (Anthrophoridae: Hymenoptera). Am Nat 111: 145-155.

2. Ward PI (1983) The effect of size on the mating behavior of the dung fly Sepsis cynipsea. Behav Ecol Sociobo 13: 75-80.

3. Collins J, Cramer J, Wechkin S (1967) Nip frequency and dominance in male swordtails and platies. Am Zool 7: 806.

4. Gandolfi G (1971) Sexual selection in relation to the social status of males in Poecilia reticulate (Teleostei: Poecilidae). Boll Zool 38: 35-48.

5. Constantz DG (1975) Behavioral ecology of mating in the male gila topminow Poeciliopsis occidentalis (Cyprinodontiformes: Poecilidae). Ecol 56: 966-973.

6. Dominey JW (1980) Female mimicry in male bluegill sunfish- a genetic polymorphism. Nat 284: 546-548.

7. Sagi A, Raanan Z (1985) Rapid identification of reproductive state and the receptive period of females in pond populations of Macrobrachium rosenbergi - a new technique. Aquacult 48: 361-367.

8. Gadgil M (1972) Male dimorphism as a consequence of sexual selection American Nat 106: 474-580.

9. Gross MR (1985) Disruptive selection for alternative life histories in salmon Nat 313: $47-48$.

10. Lucas JR, Howard RD (1995) On alternative reproductive tactics in anurans: dynamic games with density and frequency dependence. American Nat 146 365-397.

11. Gross MR (1996) Alternative reproductive strategies and tactics: diversity within sexes. Trends Ecol Evol 11: 92-98.

12. Gross MR, Repka J (1998) Game theory and inheritance of the conditional strategy. Oxford University Press, Oxford, UK.

13. Raanan Z, Sagi A (1985) Alternative mating strategies in male morphotypes of the freshwater prawn Machrobrachium rosenbergii (DeMan). Biol Bull 169 592-601.

14. Nagamine C, Knight AW, Maggenti A, Paxman G (1980) Effects of androgenic gland ablation on male primary and secondary sexual characteristics in the Malaysian prawn, Macrobrachium rosenbergii (De Man) (Decapoda, Palaemonidae), with first evidence of induced feminization in a nonhermaphroditic decapod. Gen Comp Endocrinol 41: 423-441.

15. Kuris AM, Raanan Z, Sagi A, Cohen D (1987) Morphotypic differentiation of male Malaysian Giant prawns, Macrobrachium rosenbergii. J Crust Biol 7: 219237

16. Barki A, Karplus I, Goren M (1992) Effects of size and morphotype on dominance hierarchies and resource competition in the freshwater prawn Macrobrachium rosenbergii. Anim Behav 44: 547-555. 
Citation: Soundarapandian P, Sudhakar S, Varadharajan D, Dinakaran GK (2013) Mating Behaviour in Different Size Males of Macrobrachium idae (Heller, 1862). J Cytol Histol 5: 205. doi:10.4172/2157-7099.1000205

17. Kurup BM, Harikrishnan M, Sureshkumar S (2000) Length-weight relationship of male morphotypes of Macrobrachium rosenbergii (De Man) as a valid index for differentiating their developmental pathway and growth phases. Indian J Fish 47: 283-290.

18. Karplus I, Malecha SR, Sagi A (2000) The biology and management of size variation. Agricu Res Orga, Bet-Dagan, Israel.

19. Cohen D, Raanan Z, Brody T (1981) Population profile development and morphoty differentiation in the giant freshwater prawn Macrobrachium rosenbergii (De Man). J World Maricult Soc 12: 231-243.

20. Raanan $Z$ (1982) The ontogeny of social structure in the freshwater prawn Macrobrachium rosenbergii (de Man). Ph.D. thesis, Life Sciences Institute, the Hebrew University of Jerusalem, Israel.

21. Telecky JM (1984) Alternate male reproductive strategies in the giant Malaysian prawn, Macrobrachium rosenbergii. Pacific Sci 38: 372-373.

22. Raanan Z, Cohen D (1985) The ontogeny of social structure in the freshwater prawn Macrobrachium rosenbergii, A. A. Balkema Publishers. Rotterdam, The Netherlands.

23. Dinakaran GK (2010) Mating behaviour, embryonic development, biochemical composition and mass seed production of edible prawn Macrobrachium idella idella (Hilgendorf, 1898). Ph.D Thesis, Annamalai University.

24. Atema J (1986) Review of sexual selection and chemical communication in the lobster, Homarus americanus. Can J Fish Aquat Sci 43: 2283-2390.

25. Antheunisse LJ, Van den Hoven NP, Jeffries DJ (1968) The breeding characters of Palaemonetes varians (Leach) (Decapoda, Palaemoniudae). Crust 14: 259270 .

26. Smith TIJ, Sandifer PA, Manzi JJ (1979) Epibionts of pond reared adult Macrobrachium rosenbergii (de Man) in South Carolina. Aquacult 16: 299-308.

27. Paul AJ, Paul JM (1996) Observations on mating of multiparous Chionoecetes bairdi Rathbun (Decapoda: Majidae) held with different sizes of males and oneclawed males. J Crust Biol 16: 295-299.

28. Snedden WA (1990) Determinants of male mating success in the temperate crayfish Orconectes rusticus: chela size and sperm competition. Behav 115 100-113.

29. Dinakaran GK, Soundarapandian P (2009) Mating behaviour and brood stock development of commercially important blue swimming crab Portunus sanguinolentus (Herbst). Indian J Sci Techn 2: 71-75.

30. Wade MJ, Shulter SM (2004) Sexual selection: harem size and the variance in male reproductive success. Am Nat 164: E83-89.

31. Tanaka K (2003) Population synamics of the sponge-dwelling gnathiid isopod Elaphognathia cornigera. J Mar Biol Ass Uni King 83: 95-102.

32. Shuster SM, Ballard JOW, Zinser G, Sassaman C, Keim P (2001) The influence of genetic and extrachromosomal factors on population sex ratio in Paracerceis sculpta. Crust 13: 313-326.

33. Heckenlively DB (1970) Intensity of aggregation in the Cray fish Orconectes virilis. Nat 225: 180-181.

34. Ameyaw-Akumfi C (1981) Courtship in the crayfish Procambarus clarkia (Girard) (Decapoda, Astacidae). Crust 40: 57-64.

35. Hoglund $H$ (1943) On the biology and larval development of Leander squilla (L) forma typica de Man. Svenska Hydrograp Biol Comm Scrip 2: 1-44.

36. Hamano T (1988) Mating behaviour of Oratosquilla oratoria (De Hann, 1844) (Crustacea; Stomatopoda). J Crust Biol 8: 239-244.

37. Burkenroad MD (1947) Reproductive activities of decapod Crustacea. Am Na 81: 392-398.

38. Berg AV, Sandifer PA (1984) Matting behaviour of the grass shrimp Palamonetes pugio Holthuis (Decapoda, Caridea). J Crust Biol 4: 417-424.

39. Ling SW (1969) Methods of rearing and culturing Macrobrachium rosenbergi (De Man). Ibid 3: 607-619.

40. Gleeson RA (1977) Pheromone communication in the reproductive behaviour of Callinectus sapidus. Ph.D., Dissertation, The college of William and Mary in Virginia, 1-80.

41. Bauer RT (1979) Sex attraction and recognition in the caridean shrimp Heptacarpus paludicola Holmes (Decapoda: Hippolyttidae). Mar Behav Physio 6: 157-174.
42. Beck CW (1998) Mode of fertilization and parental care in anurans Anim Behav 55: 439-449.

43. Jormalainen V (1998) Precopulatory mate guarding in crustaceans: Male competitive strategy and intersexual conflict. Quarte Revi Biol 73: 275-304.

44. Orensanz JM, Parma AM, Armstrong DA, Armstrong J, Wardrup P (1995) The breeding ecology of Cancer gracilis (Crustacea: Decapoda: Cancridae) and the mating systems of cancrid crabs. J Zool 235: 411-437.

45. Shuster SM, Wade MJ (2003) Mating Systems and Strategies, Princeton University Press.

46. Chow S, Ogasawara Y, Taki Y (1982) Male reproductive system and fertilization of the Palaemonid shrimp Macrobrachium rosenbergii. Bull Jap Soc Sci Fish 48: $177-183$.

47. Ling SW (1962) Studies on the rearing of larvae and juveniles and culturing of adults of Macrobrachium rosenbergii (De Man). Tech Pap Indo-Paci Fish Coun 57: 15.

48. Plaistow SJ, Troussard JP, Cézilly F (2001) The effect of the acanthocephalan parasite Pomphorhynchus laevis on the lipid and glycogen content of its intermediate host Gammarus pulex. Int J Parasitol 31: 346-351.

49. Borasch DJ, Teoto-Nio H, Rose MR, Mueller LE (2000) Density-dependent natural selection in Drosophila, correlations between feeding rate, development time and viability. J Evol Biol 13: 181-187.

50. Peckol EL, Troemel ER, Bargmann Cl (2001) Sensory experience and sensory activity regulate chemosensory receptor gene expression in Caenorhabditis elegans. Proc Natl Acad Sci U S A 98: 11032-11038.

51. Nephew BC, Romero LM (2003) Behavioral, physiological, and endocrine responses of starlings to acute increases in density. Horm Behav 44: 222-232.

52. Giorgi D, Rouquier S (2002) Identification of V1R-like putative pheromone receptor sequences in non-human primates. Characterization of V1R pseudogenes in marmoset, a primate species that possesses an intact vomeronasal organ. Chem Sen 27: 529-537.

53. Haig D, Bergstrom CT (1995) Multiple mating, sperm competition and meiotic drive. J Evol Biol 8: 265-282.

54. Shuster SM (1981) Sexual selection in the Socorro Isopod, Thermosphaeroma thermophilum (Cole and Bane) (Crustacea: Peracarida). Anim Behav 29: 698707

55. Shuster SM (1992) The reproductive behaviour of $\alpha$, $\beta$-, and $y$-males in Paracerceis sculpta, a marine isopod crustacean. Behav 121: 231-258.

56. Borowsky B (1980) The pattern of tube-sharing in Microdeutopus gryllotalpa (Crustacea: Amphipoda). Anim Behav 28: 790-797.

57. Kurdziel JP, Knowles LL (2002) The mechanisms of morph determination in the amphipod Jassa: implications for the evolution of alternative male phenotypes. Proc Biol Sci 269: 1749-1754.

58. Koga T, Henmi Y, Murai M (1993) Sperm competition and the assurance of underground copulation in the sand-bubbler crab, Scopiemera globosa (Brachyura: Ocypodidae). J Crust Biol 13: 134-137.

59. Ahl JSB, Laufer H (1996) The pubertal molt in Crustacea revisited. Invert Repr Devel 30: 177-180.

60. Correa CJ, Baeza A, Hinojosa IA, Thiel M (2003) Male dominance hierarchy and mating tactics in the Rock Shrimp, Rhynchocinetes typus (Decapoda: Caridea). J Crust Biol 23: 33-45.

61. Borgia G (1981) Sexual competition in Scazophaga stercoraria: female choiceina male-controlled system. Anim Behav 29: 71-80.

62. Maynard Smith J, Price GR (1973) The logic of animal conflict. Nat 246: 15-18 McNally and Co., New York, USA. 